\title{
Lodenafil Carbonate Tablets: Optimization and Validation of a Capillary Zone Electrophoresis Method
}

\author{
Cristiane F. Codevilla,* Pâmela Cristina L. Ferreira, Maximiliano S. Sangoi, \\ Pedro Eduardo Fröehlich and Ana Maria Bergold
}

\author{
Faculdade de Farmácia, Universidade Federal do Rio Grande do Sul, \\ 90610-000 Porto Alegre-RS, Brazil
}

\begin{abstract}
Um método simples de eletroforese capilar de zona (CZE) foi desenvolvido e validado para análise de carbonato de lodenafila em comprimidos. A metodologia de superfície de resposta foi utilizada para a otimização do $\mathrm{pH}$, concentração do tampão, voltagem e temperatura. O método utilizou como eletrólito, tampão borato $50 \mathrm{mmol} \mathrm{L}^{-1}, \mathrm{pH} \mathrm{10}$, voltagem de $15 \mathrm{kV}$. A separação foi efetuada em capilar de sílica fundida mantida a $32,5^{\circ} \mathrm{C}$ e o comprimento de onda de detecção foi de $214 \mathrm{~nm}$. O método foi validado, demonstrando especificidade, linearidade $(\mathrm{r}=0,9995)$, precisão (desvio padrão relativo inferior a $2 \%$ ) e exatidão (99,95\%). O método demonstrou ser robusto, através de avaliação por planejamento fatorial fracionário. O método CZE proposto foi aplicado com sucesso para a análise quantitativa de carbonato de lodenafila em comprimidos e os resultados, comparados com os métodos por cromatografia líquida de alta eficiência e espectrofotometria no ultravioleta, não apresentaram diferença significativa.
\end{abstract}

A simple capillary zone electrophoresis (CZE) method was developed and validated for the analysis of lodenafil carbonate in tablets. Response surface methodology was used for optimization of the $\mathrm{pH}$ and concentration of the buffer, applied voltage and temperature. The method employed $50 \mathrm{mmol} \mathrm{L}^{-1}$ borate buffer at $\mathrm{pH} 10$ as background electrolyte with an applied voltage of $15 \mathrm{kV}$. The separation was carried out in a fused-silica capillary maintained at $32.5^{\circ} \mathrm{C}$ and the detection wavelength was $214 \mathrm{~nm}$. The method was validated showing specificity, linearity $(\mathrm{r}=0.9995)$, precision (relative standard deviation less than $2 \%$ ) and accuracy $(99.95 \%)$. The method proved to be robust by a fractional factorial design evaluation. The proposed CZE method was successfully applied for the quantitative analysis of lodenafil carbonate in tablets and the results compared to the high performance liquid chromatography and ultraviolet spectrophotometric methods, showed non-significant differences.

Keywords: capillary zone electrophoresis, experimental design, lodenafil carbonate, optimization, validation

\section{Introduction}

Capillary electrophoresis (CE) has become one of the most advanced separation techniques for pharmaceutical analysis, although quality control analysis of pharmaceuticals currently is performed predominantly with high-performance liquid chromatography (HPLC). ${ }^{1,2}$ It has been proven that $\mathrm{CE}$ is a useful and reliable alternative and a complementary technique to HPLC in many areas, including the determination of the active pharmaceutical ingredients, drug related impurities, enantiomeric separations, identity confirmation and

*e-mail: cristianefc@ hotmail.com stoichiometry determination. ${ }^{3-6} \mathrm{CE}$ has many advantages such as high efficiency, high resolution, rapid analysis and low consumption of sample and reagents. ${ }^{7,8}$

The optimization of separation with $\mathrm{CE}$ is complex and difficult, because a high number of parameters, such as temperature, $\mathrm{pH}$, voltage and buffer composition affect the separation. Rather than following the conventional monovariate approach used to adjust the parameters, thus involving a large number of independent analyses, one could advantageously replace the procedure by statistically designed experimental protocols, in which several factors are simultaneously varied. The use of an experimental design can be extremely beneficial in developing capillary electrophoretic methods. ${ }^{9}$ 
Response surface methodology is a collection of statistical and mathematical techniques useful for developing, improving and optimizing processes, interpreting the relationships between the responses and factor effects and simultaneously optimizing the levels of variables to achieve the best system performance. ${ }^{10,11}$

Erectile dysfunction (ED) is defined by the National Institutes of Health as the inability to achieve and maintain an erection sufficient for satisfactory sexual intercourse. ${ }^{12}$ ED is not a life-threatening disorder, but it influences the patient's daily routine, social interactions, well-being and quality of life. ${ }^{13}$ It may often be the first manifestation of important systemic (in advancing age) or relational (in younger age) pathologies and it is considered a possible marker of clinically undiagnosed disease, thus representing the 'tip of the iceberg' of a systemic vascular disorder. ${ }^{14,15}$

In 1998, a new class of drugs, the phosphodiesterase type 5 inhibitors (PDE5 inhibitors) was introduced. The PDE5 inhibitors have revolutionized the way in which men with ED can be treated. ${ }^{16,17}$ The advent of these highly efficacious and relatively safe compounds had a profound impact on the diagnosis and treatment of ED. ${ }^{18}$

Lodenafil (bis-(2-\{4-[4-ethoxy-3-(1-methyl-7-oxo-3propyl-6,7-dihydro-1 $H$-pyrazolo [4,3-d]pyrimidin-5-yl)benzenesulfonyl]piperazin-1-yl\}-ethyl) carbonate (Figure 1) is a PDE5 inhibitor developed in Brazil, which is a dimer formed by two lodenafil molecules linked by a carbonate bridge. Lodenafil carbonate (LOC) is a product that after ingestion delivers the active compound lodenafil. ${ }^{19,20}$

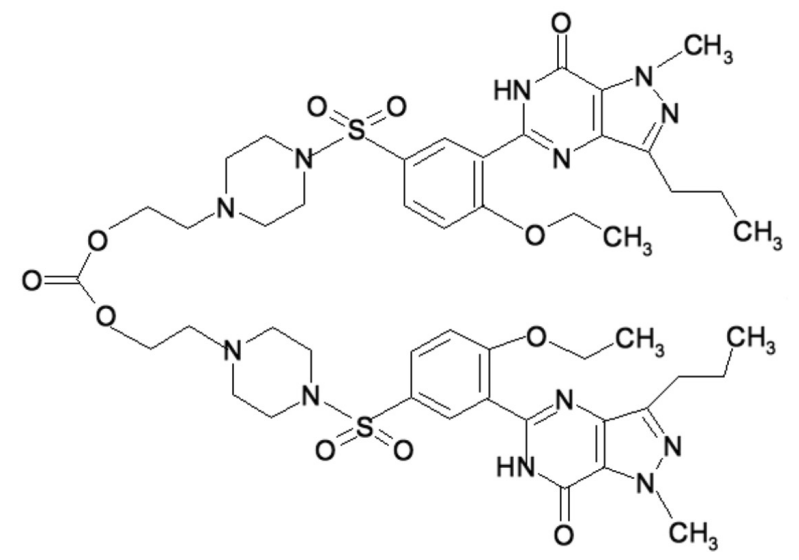

Figure 1. Chemical structure of lodenafil carbonate.

Little has been published until now concerning the detection of LOC in pharmaceutical preparations ${ }^{21,22}$ and biological samples. ${ }^{19}$ These studies involve UV spectrophotometric and HPLC method for the determination of LOC.

This work proposes the development, optimization and validation of a capillary zone electrophoresis
(CZE) method for the determination of LOC in tablets, establishing a comparison with the validated HPLC and UV spectrophotometric methods.

\section{Experimental}

\section{Chemicals and reagents}

LOC (lodenafil carbonate) used as reference substance was kindly supplied by Cristália Produtos Químicos Farmacêuticos LTDA (São Paulo, Brazil) and nimesulide reference standard, used as internal standard (IS), was purchased from United States Pharmacopeia (USP, Rockville, USA). The tablets of Helleva ${ }^{\circledR}$ (Cristália Produtos Químicos Farmacêuticos LTDA, São Paulo, Brazil) containing LOC (80 mg per tablet, excipients: calcium phosphate dibasic dihydrate, povidone, lactose, colloidal silicon dioxide, sodium croscarmellose, microcrystalline cellulose and magnesium stearate) were obtained commercially. All chemicals used were of pharmaceutical or special analytical grade. Throughout the study, water was obtained from a Milli-Q system from Millipore (Bedford, USA). Before analysis, all the solutions were filtered through $0.22 \mu \mathrm{m}$ Millex filter (Millipore).

\section{Apparatus and electrophoretic conditions}

CZE (capillary zone electrophoresis) experiments were performed on an Agilent ${ }^{3 \mathrm{D}} \mathrm{CE}$ apparatus (Agilent Technologies, Waldbronn, Germany) equipped with an autosampler, a photodiode array (PDA) detector, and power supply able to deliver up to $30 \mathrm{kV}$. CE ChemStation software was used for instrument control, data acquisition and analysis.

Electrophoretic separations were carried out with a fused-silica capillary with $50 \mu \mathrm{m}$ i.d. and $48.5 \mathrm{~cm}$ of total length (effective length $40 \mathrm{~cm}$ ), thermostatized at $32.5^{\circ} \mathrm{C}$, and with detection set at $214 \mathrm{~nm}$ using a PDA detector. Hydrodynamic injection of sample was performed at $50 \mathrm{mbar}$ for $5 \mathrm{~s}$ and a constant voltage of $15 \mathrm{kV}$ was applied during the analysis. At the beginning of each working day, the capillary was rinsed sequentially with $0.1 \mathrm{~mol} \mathrm{~L}^{-1}$ sodium hydroxide for $15 \mathrm{~min}$, followed by water for $15 \mathrm{~min}$, and then with running electrolyte solution for $15 \mathrm{~min}$. To achieve high migration time reproducibility between injections, the capillary was conditioned with $0.1 \mathrm{~mol} \mathrm{~L}^{-1}$ sodium hydroxide (2 $\mathrm{min})$, water (1 $\mathrm{min})$, and a running BGE solution (2 min). Because electrolysis can change the electroosmotic flow (EOF) and affect the migration time, efficiency, and selectivity, the running electrolyte solution was replaced by a fresh solution after every three injections. 


\section{Background electrolyte solution preparation}

The optimized background electrolyte (BGE) solution used in this analysis was $50 \mathrm{mmol} \mathrm{L}^{-1}$ boric acid at $\mathrm{pH} 10$. To prepare this solution $0.154 \mathrm{~g}$ of boric acid was diluted with $40 \mathrm{~mL}$ of water. The $\mathrm{pH}$ was adjusted to 10 by adding $0.1 \mathrm{~mol} \mathrm{~L}^{-1}$ sodium hydroxide and the volume completed to $50 \mathrm{~mL}$ with ultrapure water. The solution was daily prepared and filtered.

\section{Preparation of reference substance solutions}

Standard stock solution of LOC was prepared by accurately weighing $10 \mathrm{mg}$ of LOC transferred to a $100 \mathrm{~mL}$ volumetric flask with $0.1 \mathrm{~mol} \mathrm{~L}^{-1}$ sodium hydroxide $\left(100 \mu \mathrm{g} \mathrm{mL} \mathrm{m}^{-1}\right)$. A standard stock solution of nimesulide $\left(1 \mathrm{mg} \mathrm{mL}^{-1}\right.$ ) was prepared in methanol. All solutions were stored at $2-8{ }^{\circ} \mathrm{C}$, protected from light and diluted daily to an appropriate concentration with background electrolyte solution.

\section{Sample preparation}

Twenty tablets of Helleva ${ }^{\circledR}$ were finely powdered. A weighed portion of the powder, equivalent to $10 \mathrm{mg}$ of LOC was transferred to a $100 \mathrm{~mL}$ volumetric flask. With the addition of $50 \mathrm{~mL}$ of sodium hydroxide, the mixture was sonicated for $10 \mathrm{~min}$, and filtered. The sample stock solution prepared with the final concentration of $100 \mu \mathrm{g} \mathrm{mL} \mathrm{m}^{-1}$ of LOC was stored at $2-8{ }^{\circ} \mathrm{C}$, protected from light and diluted daily to an appropriate concentration with BGE.

\section{Statistical software and design of experiment for method optimization}

All the experimental designs, graphical and statistical analysis of the data were performed by Minitab 14 (Minitab Inc, State College, PA, USA) data analysis software system.

Factorial designs are the most useful schemes for the optimization of variables with a limited number of experiments. A variety of factorial designs are available to accomplish this task. The most successful and best among them is the central composite design, which is accomplished by adding two experimental points along each coordinate axis at opposite sides of the origin and at a distance equal to the semi-diagonal of the hyper cube of the factorial design and new extreme values ( $\alpha$; low and high) for each factor added in this design. This first experimental design was carried out to optimize the electrophoretic conditions with high sensitivity, efficiency and short run time. A second order polynomial was used to fit the data. Treatment allocation with their respective experimental values is shown in Table 1.

Table 1. Nominal values corresponding to $-1,0,+1,-\alpha$ and $+\alpha$ of central composite design for method optimization

\begin{tabular}{lccccc}
\hline CE factor & $-\alpha$ & -1 & 0 & +1 & $+\alpha$ \\
\hline $\mathrm{pH}$ borate buffer & 9.2 & 9.6 & 10.0 & 10.4 & 10.8 \\
Borate buffer $/\left(\mathrm{mmol} \mathrm{L}^{-1}\right)$ & 40 & 45 & 50 & 55 & 60 \\
Capillary temperature $/{ }^{\circ} \mathrm{C}$ & 27.5 & 30 & 32.5 & 35 & 37.5 \\
Voltage / kV & 7.5 & 10 & 12.5 & 15 & 17.5 \\
\hline
\end{tabular}

$\alpha=\left(2^{\mathrm{k}}\right)^{1 / 4}$, where $\mathrm{k}=4$ factors: $\alpha=2.0$.

\section{Validation}

To demonstrate the suitability of this method for pharmaceutical quality control, it was validated with respect to specificity, linearity, precision, accuracy, and robustness, according to the International Conference on Harmonisation ( $\mathrm{ICH}$ ) recommendations, at the optimized operating conditions. ${ }^{23}$

\section{Specificity}

The specificity of the method was investigated by analyzing a placebo solution containing all the tablet components except LOC. In addition, the specificity was assessed by observing potential interferences between LOC and degradation products obtained, when standard solutions of LOC were stressed by acidic, basic, oxidative and UV light conditions. Solutions of LOC in $1.0 \mathrm{~mol} \mathrm{~L}^{-1}$ hydrochloric acid and $1.0 \mathrm{~mol} \mathrm{~L}^{-1}$ sodium hydroxide were exposed at $60{ }^{\circ} \mathrm{C}$ for $5 \mathrm{~h}$. Oxidative degradation was induced by storing the solutions in $0.1 \%$ potassium permanganate at room temperature for $15 \mathrm{~min}$, protected from light. Photolytic studies were done by exposing the sample solution to a $254 \mathrm{~nm}$ UV lamp for $15 \mathrm{~min}$, in a photostability chamber. The samples were analyzed against a freshly prepared control sample (with no degradation treatment).

\section{Linearity}

Linearity was tested on three different days at 7 concentration levels of LOC (20-80 $\left.\mathrm{g} \mathrm{mL}^{-1}\right)$ and spiked with a constant concentration of nimesulide $\left(50 \mu \mathrm{g} \mathrm{mL}^{-1}\right)$ used as internal standard. Each concentration level was injected in triplicate. The peak area ratio of LOC reference substance to the IS, against the respective reference concentrations, was used for plotting the graph, and the linearity was evaluated by the least square regression analysis. 


\section{Precision}

The precision expressed as the relative standard deviation of peak area measurements was evaluated under repeatability and intermediate precision conditions. For repeatability studies, six replicate experiments were carried out on the same day. The intermediate precision was performed by comparing the results of the assay on 3 different days.

\section{Accuracy}

The accuracy of the developed method was evaluated by a recovery test. The sample solutions were fortified with three known concentrations of reference standard corresponding to 75,100 and $125 \%$ of the sample concentration $\left(50 \mu \mathrm{g} \mathrm{mL} \mathrm{mL}^{-1}\right)$.

\section{Robustness}

In order to study the simultaneous variation of the factors in the considered responses, a multivariate approach using design of experiments is recommended in robustness testing. The procedure selected was a 2-level $2^{4-1}$ fractional factorial design performed by the selection of four factors, studied at two levels (high and low): borate buffer concentration $\left(48 ; 52 \mathrm{mmol} \mathrm{L}^{-1}\right), \mathrm{pH}$ borate buffer $(9.8 ; 10.2)$, capillary temperature $\left(31 ; 34^{\circ} \mathrm{C}\right)$, and voltage $(13 ; 17 \mathrm{kV})$. The ranges examined were small deviations from the method settings. A center point with the optimized conditions was also added to the factorial design (nine experiments). The response is the percentage of LOC in the tablets (relative to their label claimed concentration) obtained by the comparison with the reference solution in each experiment. All experiments were performed in randomized order to minimize the effects of uncontrolled factors that may introduce a bias into the response. The statistical analyses of the data were performed by the MINITAB 14 (Minitab Inc, State College, PA, USA) data analysis software.

\section{Results and Discussion}

The optimization of a CZE separation condition is a critical step, since the wide array of variables, such as applied voltage, buffer composition and temperature, can influence the separation efficiency, migration time and resolution. ${ }^{24}$ Central composite designs are by far the most widely used methods for the optimization of CZE separations since they offer the possibility of evaluating the curvature of the data and fitting the experimental points to response surfaces. ${ }^{25}$

The CZE method parameters for determination of the LOC were optimized to obtain the best efficiency, symmetry and resolution within the minimum analysis time. The optimization procedure was comprised of two steps: initial experiments and experimental design.

The aim of the initial experiments was to establish the basic analytical requirements $(\mathrm{pH}$ range, type of buffer) of the method. Some buffer systems containing sodium phosphate, sodium citrate, sodium acetate, sodium tetraborate, ammonium acetate or boric acid were investigated in the $\mathrm{pH}$ range from 5-10 at different concentrations (10-50 $\left.\mathrm{mmol} \mathrm{L}^{-1}\right)$. The use of borate buffer

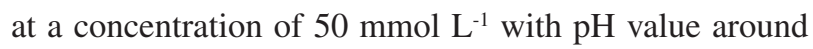
10 (at a temperature of $32.5^{\circ} \mathrm{C}, 12.5 \mathrm{kV}$ ) resulted in high sensitivity and good peak symmetry of LOC.

After a small number of runs and the selection of basic electrophoretic conditions, a central composite design was applied to optimize the main variables that could influence the LOC analyses by CZE: pH borate buffer, borate buffer concentration, capillary temperature and voltage. A response surface methodology was carried out to obtain more information and to investigate the behavior of the response around the nominal values of the factors. Response surface methodology has the following advantages: $(i)$ to allow a complete study where all interaction effects are estimated, and (ii) to give an accurate description of an experimental region around a center of interest with validity of interpolation. ${ }^{26,27}$ The criterion to select the optimum values for the studied variables was based on obtaining a maximum for a multiple response function established, since LOC were easily separated from degradation products showing adequate efficiency (number of theoretical plates), tailing factor and short analysis time. Experiments were performed according to the experimental plan determined by Minitab software. Significant changes in migration time and tailing factor were observed for all the combinations, implying that these variables significantly affected the electrophoretic pattern.

From the optimization procedure, $\mathrm{pH}$, buffer concentration and separation voltage were found significant on efficiency with optimum values of $50 \mathrm{mmol} \mathrm{L}^{-1}$ borate buffer at $\mathrm{pH} 10$ with an applied voltage of $15 \mathrm{kV}$ and capillary temperature of $32.5^{\circ} \mathrm{C}$. Under these conditions, efficiencies higher than 80000 , good symmetry (around 1.0) and lower migration time (approximately $4 \mathrm{~min}$ ) were achieved. Some of the estimated response surfaces from which the above mentioned optimum values have been obtained are shown in Figure 2.

\section{Method validation}

\section{Specificity}

The specificity of the method indicates the ability to accurately measure the analyte response in the presence of 

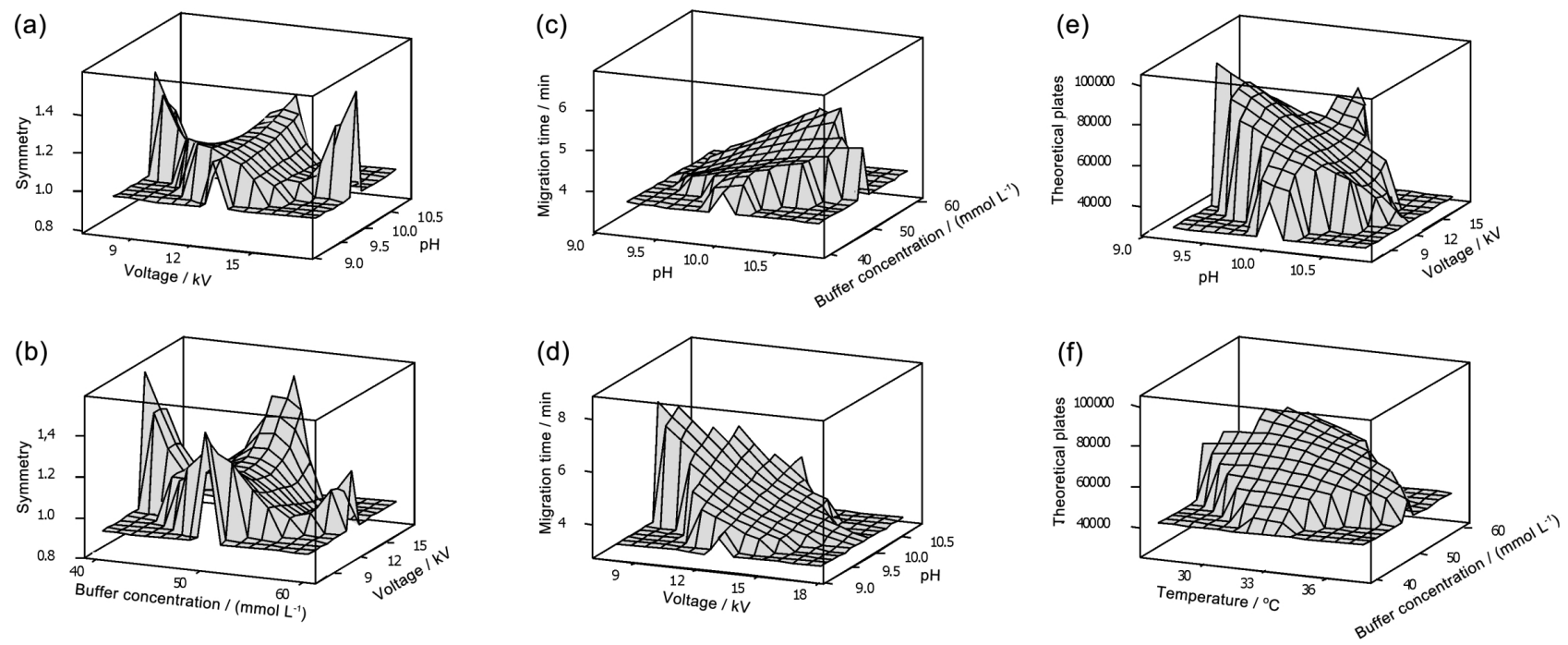

Figure 2. Estimated response surfaces obtained in the optimization procedure. Symmetry: (a) voltage $v s$. $\mathrm{pH}$, (b) buffer concentration $v s$. voltage. Migration time: (c) $\mathrm{pH} v s$. buffer concentration, (d) voltage $v s$. $\mathrm{pH}$. Theoretical plates: (e) $\mathrm{pH} v s$. voltage; (f) temperature $v s$. buffer concentration.

potentially interfering sample components or degradation products. The specificity was evaluated by stressing the analyte under acidic, basic, oxidative and photolytic conditions. Chromatographic runs of a placebo solution were also performed. Figure 3 shows that the acidic, basic and oxidative conditions resulted in a decreased area without any additional peak, indicating that the degradation products (DP) were not detected by UV or the degradation products did not migrate in the CZE method. The photolytic condition exhibited a significant decrease of the area, and two additional peaks were detected at 5.8 and $6.3 \mathrm{~min}$ (Figure 3). In all cases the purity of LOC was assessed with the PDA detector, demonstrating that the proposed method is specific for the analysis. The chromatographic run of a placebo solution showed no interference of the excipients with the elution of LOC.

\section{Linearity}

Linearity was investigated in the concentration range of 20-80 $\mu \mathrm{g} \mathrm{mL}^{-1}$ for LOC, and $50 \mu \mathrm{g} \mathrm{mL}^{-1}$ of nimesulide was added as IS in all cases. The linearity curve was defined by the equation of $y=0.019 x+0.038$, where $y$ is the peak area ratio of LOC to IS, and $x$ is the concentration of LOC expressed in $\mu \mathrm{g} \mathrm{mL}^{-1}$. The correlation coefficient was 0.9995 . The validity of the assay was verified by means of analysis of variance (ANOVA), which demonstrated significant linear regression $(\mathrm{p}<0.05)$ and no significant linearity deviation $(\mathrm{p}>0.05)$. The limit of detection (LOD) was based on the standard deviation of the response and the slope of the constructed calibration curve, as described in International Conference on Harmonization guidelines. ${ }^{23}$ The LOD achieved was $1.36 \mu \mathrm{g} \mathrm{mL}^{-1}$.

\section{Precision}

The precision of the method for LOC determination was evaluated using the results obtained over 1 day of operation under the same conditions (intra-assay) and for 3 days (inter-assay). The results expressed as the relative standard deviation (RSD \%) are given in Table 2, and indicate that the method has repeatability and intermediate precision.

\section{Accuracy}

A LOC sample solution was fortified with three solutions at known concentrations and at three different levels. The recovery of added standard was determined in triplicate analysis and the results are shown in Table 3.

\section{Robustness}

The susceptibility to change of the analytical method developed was tested in order to evaluate the robustness. For this purpose a 2-level $2^{4-1}$ fractional factorial design was employed. The experimental plan and the corresponding responses are summarized in Table 4.

The significance of the effects was evaluated by a Pareto chart of the standardized effects and normal probability plot of the residuals. The Pareto graph (Figure 4a) consists of bars with a length proportional to the absolute value of the estimated effect, divided by the pseudo standard error defined by Lenth (Lenth's PSE). ${ }^{28}$ Codes A, B, C, and D correspond to the borate buffer concentration, $\mathrm{pH}$ borate buffer, capillary temperature and voltage, respectively. The combination of two codes indicates the interaction effect between the two variables. The bars were displayed based on the size of the effect, with the largest effect at the top. The chart includes a vertical line at the critical $t$-value for 


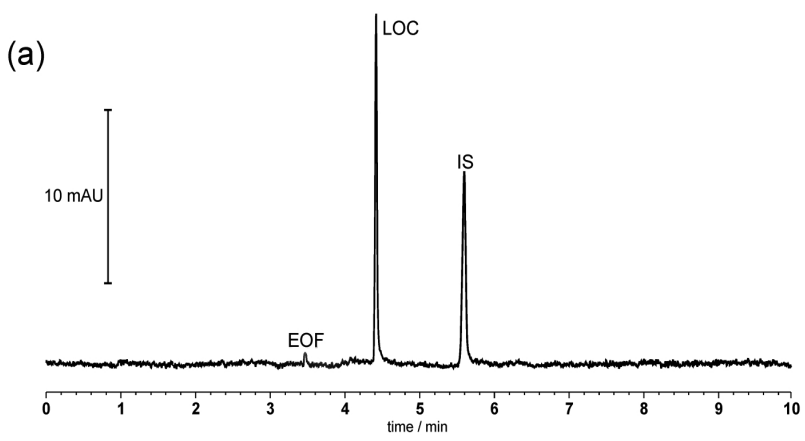

(b)

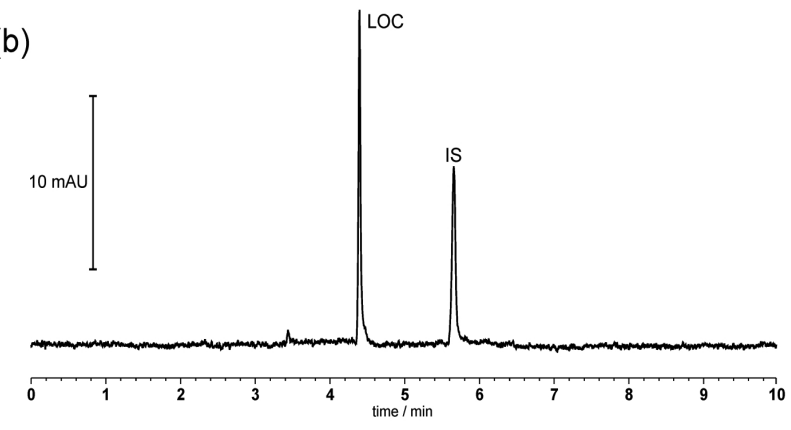

(c)

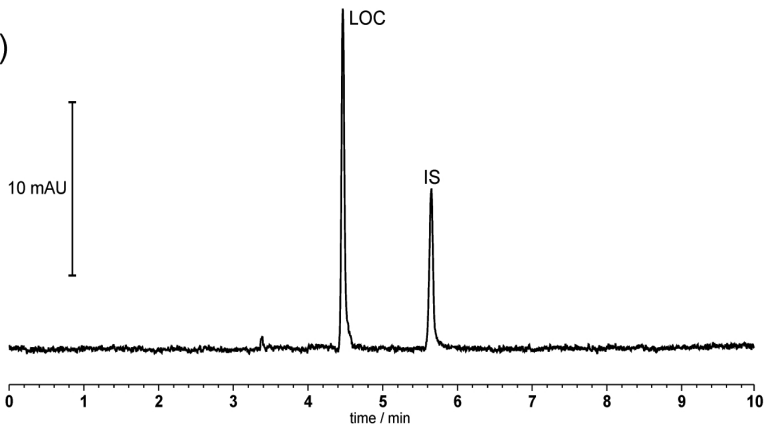

(d)

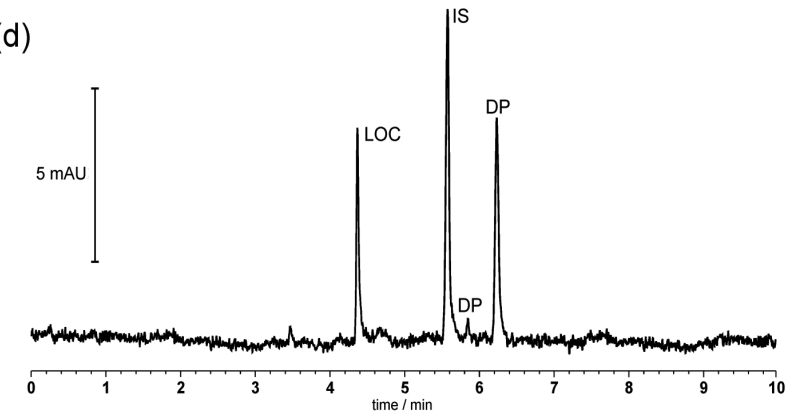

(e)

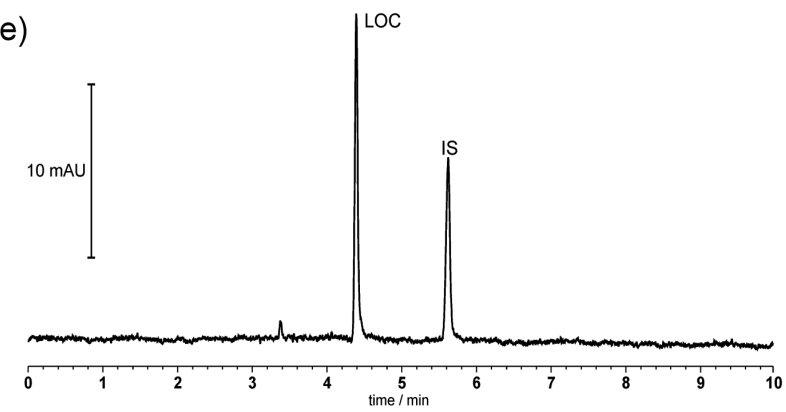

Figure 3. CZE electropherograms of LOC $\left(50 \mu \mathrm{g} \mathrm{mL}^{-1}\right)$ and nimesulide $\left(50 \mu \mathrm{g} \mathrm{mL}^{-1}\right)$ : (a) LOC reference substance, (b) LOC after acidic hydrolysis, (c) LOC after basic hydrolysis, (d) LOC after photodegradation condition, (e) LOC after oxidative condition.
Table 2. Method repeatability/intermediate precision for lodenafil carbonate

\begin{tabular}{lccc}
\hline \multirow{2}{*}{ Sample } & \multicolumn{3}{c}{ Label claim /\% } \\
\cline { 2 - 4 } 1 & Day 1 & Day 2 & Day 3 \\
\hline 2 & 105.8 & 105.9 & 106.5 \\
3 & 105.4 & 105.4 & 106.9 \\
4 & 108.8 & 104.0 & 105.6 \\
5 & 107.8 & 109.1 & 104.7 \\
6 & 104.6 & 108.5 & 105.8 \\
Mean (6) & 107.4 & 106.4 & 107.5 \\
\% RSD & 106.6 & 108.0 & 106.0 \\
Mean (18) & 1.65 & 1.32 & 1.34 \\
\% RSD & 106.5 & & \\
\hline
\end{tabular}

Table 3. Accuracy data

\begin{tabular}{lccc}
\hline $\begin{array}{l}\text { Concentration / } \\
\%\end{array}$ & $\begin{array}{c}\text { Amount added } \\
\text { concentration }^{\mathrm{a}} / \\
\left(\mu \mathrm{g} \mathrm{mL}^{-1}\right)\end{array}$ & $\begin{array}{c}\text { Amount found } \\
\text { concentration }^{\mathrm{a}} / \\
\left(\mu \mathrm{g} \mathrm{mL}^{-1}\right)\end{array}$ & $\begin{array}{c}\text { Recovery / } \\
\%\end{array}$ \\
\hline 70 & 12.5 & 12.42 & 99.4 \\
100 & 25 & 25.17 & 100.7 \\
125 & 37.5 & 37.42 & 99.8 \\
\hline
\end{tabular}

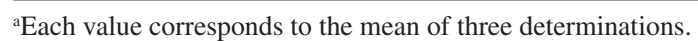

$\alpha$ equal 0.05. Effects in which the bars are smaller than the critical $t$-value were not considered significant and did not affect the response variables. Figure $4 \mathrm{~b}$ presents the normal probability plot of residuals for LOC. At the studied ranges, the effects of the factors were not statistically significant ( $\alpha=0.05$ ) for the response studied, assay (\%). Therefore, there were no significant changes in the assay regarding the percentage of LOC contents in the modifications made under the experimental conditions showing the robustness of the developed method.

Comparison between the CZE method, UV-spectrophotometric method and HPLC method

The results obtained from the CZE method were compared statistically with the HPLC and UV spectrophotometric method published previously, ${ }^{21,22}$ and no evidence of significant difference was observed. The calculated $F$-value $(F$ calculated $=1.73987)$ was found to be less than the critical $F$-value $(F$ critical $=3.35413)$ at $5 \%$ of significance level. Thus, the proposed method is appropriate for the determination of LOC in tablets and can be used in routine quality control. 
Table 4. Selected 2-level $2^{4-1}$ fractional factorial design for the robustness testing of lodenafil carbonate

\begin{tabular}{|c|c|c|c|c|c|}
\hline Experiment & $\begin{array}{l}\text { Borate buffer } \\
\text { concentration / } \\
\left(\mathrm{mmol} \mathrm{L}^{-1}\right)\end{array}$ & $\begin{array}{l}\mathrm{pH} \text { borate } \\
\text { buffer }\end{array}$ & $\begin{array}{c}\text { Capillary } \\
\text { Temperature } /{ }^{\circ} \mathrm{C}\end{array}$ & Voltage / kV & Assay / \% \\
\hline 1 & 52 & 9.8 & 34 & 13 & 107.03 \\
\hline 2 & 48 & 10.2 & 34 & 13 & 106.87 \\
\hline 3 & 52 & 10.2 & 31 & 13 & 107.61 \\
\hline $4^{a}$ & 50 & 10.0 & 32.5 & 15 & 107.45 \\
\hline 5 & 48 & 10.2 & 31 & 17 & 106.78 \\
\hline 6 & 48 & 9.8 & 34 & 17 & 107.99 \\
\hline 7 & 52 & 10.2 & 34 & 17 & 106.30 \\
\hline 8 & 52 & 9.8 & 31 & 17 & 107.90 \\
\hline 9 & 48 & 9.8 & 31 & 13 & 106.69 \\
\hline
\end{tabular}

aptimized conditions.

(a)

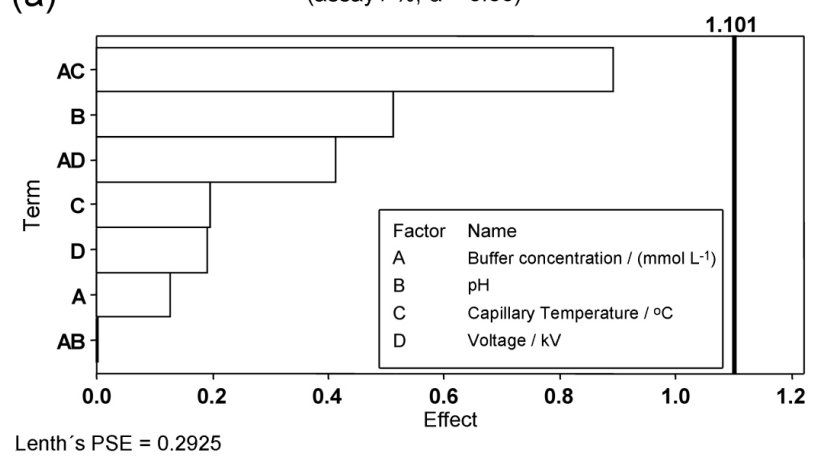

(b)

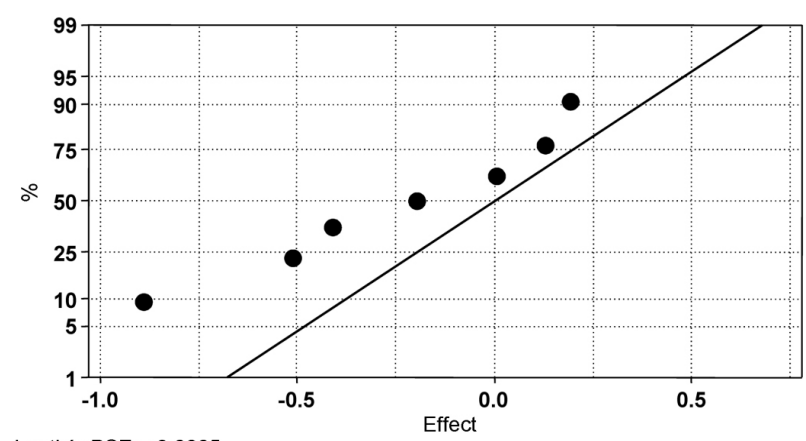

Lenth's PSE $=0.2925$

Figure 4. Pareto charts (a) and normal probability plot (b) representing the effects of the variables and their interactions on the LOC assay for the robustness test using the fractional factorial design 2-level $2^{4-1}$ (nine experiments).

\section{Conclusions}

In this study, a capillary zone electrophoresis method for quality control of LOC was developed. The method was optimized by using response surface methodology, which made it possible to achieve good efficiency, high sensitivity and short analysis time. The method was validated following ICH guidelines and showed sufficient linearity, accuracy, precision, specificity and robustness. Compared with the validated HPLC and UV spectrophotometric methods, the CZE method has some advantages including the use of smaller amounts of sample and reagents and the employment of an aqueous system rather than the potentially toxic organic solvents. Thus, this method is a suitable alternative for routine quality control of LOC in pharmaceutical formulations.

\section{Acknowledgments}

The authors wish to thank the Cristália Laboratories (Brazil) for the supply of the reference substance and the $\mathrm{CNPq}$ for the financial support.

\section{References}

1. Zhang, Q.; Li, Y. F.; Huang, C. Z.; Talanta 2008, 76, 44.

2. Ruiz, T. P.; Lozano, C. M.; Sanz, A.; Bravo, E.; J. Pharm. Biomed. Anal. 2004, 34, 891.

3. Boone, C. M.; Waterval, J. C. M.; Lingeman, H.; Ensing, K.; Underberg, W. J. M.; J. Pharm. Biomed. Anal. 1999, 20, 831.

4. Altria, K. D.; Elder, D.; J. Chromatogr., A 2004, 1023, 1.

5. Morzunova, T. G.; Pharm. Chem. J. 2006, 40, 158.

6. Suntornsuk, L.; Anal. Bioanal. Chem. 2010, 398, 29.

7. Holland, L. A.; Chetwyn, N. P.; Perkins, M. D.; Lunte, S. M.; Pharm. Res. 1997, 14, 372.

8. Yang, X. J.; Chen, Z. G.; Liu, C.; Li, O. L.; Talanta 2010, 82, 1935.

9. Mamani, M. C. V.; Farfan, J. A.; Reyes, F. G. R.; Silva, J. A. F.; Ratha, S.; Talanta 2008, 76, 1006.

10. Bas, D.; Boyac, I. H.; J. Food Eng. 2007, 78, 836. 
11. Palabiyik, I. M.; Onur, F.; Anal. Sci. 2010, 26, 853.

12. NIH Consensus Conference; JAMA, J. Am. Med. Assoc. 1993, $270,83$.

13. Albersen, M.; Mwamukonda, K. B.; Shindel, A. W.; Lue, T. F.; Med. Clin. North Am. 2011, 95, 201.

14. Aytac, I. A.; Mckinlay, J. B.; Krane, R. J.; BJU Int. 1999, 84, 50.

15. Berookhim, B. M.; Bar-Chama, N.; Med. Clin. North Am. 2011, 95, 213.

16. Brock, G.; Eur. Urol. Suppl. 2002, 1, 12.

17. Eardley, I.; J. Mens Health Gend 2006, 3, 323.

18. Gooren, L.; J. Mens Health 2008, 5, 163.

19. Toque, H.; Teixeira, C. E.; Lorenzetti, R.; Okuyama, C. E.; Antunes, E.; De Nucci, G.; Eur. J. Pharmacol. 2008, 591, 189.

20. Glina, S.; Toscano, I.; Gomatzky, C.; Góes, P. M; Nardozza Jr., A.; Claro, J. F. A.; Pagani, E.; J. Sex. Med. 2009, 6, 553.
21. Codevilla, C. F.; Lemos, A. M.; Delgado, L. S.; Rolim, C. M. B.; Adams, A. I. H.; Bergold, A. M.; J. Chromatogr. Sci. 2011, 49, 502.

22. Codevilla, C. F.; Castilhos, T. S.; Fröehlich, P. E.; Bergold, A. M.; J. Pharm. Res. 2011, 4, 2368.

23. International Conference on Harmonization; ICH Q2 (R1): Validation of Analytical Procedures-Text and Methodology, Geneva, Switzerland, 2005.

24. Gong, W. J.; Zhang, Y. P.; Choi, S. H.; Zhang, Y. J.; Lee, K. P.; Microchim. Acta 2007, 156, 327.

25. Sentellas, S.; Saurina, J.; J. Sep. Sci. 2003, 26, 875.

26. Fabre, H.; J. Pharm. Biomed. Anal. 1996, 14, 1125.

27. Lin, D. K. J.; J. Qual. Technol. 1999, 31, 61.

28. Lenth, R. V.; Technometrics 1989, 31, 469.

Submitted: July 4, 2012

Published online: December 12, 2012 